\title{
Exploration and Practice of engineering ability development for department of electrical engineering
}

\author{
Lei Shaolan, He Juan,He Xiaorong, Li Shan \\ School of Electronic Information and Automation,Chongqing University of Technology, \\ Chongqing 400054,China \\ leishaolan@cqut.edu.cn, applehej@163.com, hexiaorong@cqut.edu.cn, lishan@cqut.edu.cn
}

\begin{abstract}
According to educating and training aim of ministry of education "outstanding engineers" and combining with professional characteristic of electrical subject, this paper introduces the " $2+1+1$ " educating model of outstanding engineers for the department of electrical engineering and automation in Chongqing University of Technology(CQUT). The selecting principles and procedures of outstanding engineers are established, and the practical project of outstanding engineers training on electrical engineering and automation in CQUT is founded. As a result, the educating and training project of the department of electrical engineering and automation in CQUT is hoped to be continually perfected by exploration and practice.
\end{abstract}

Keywords- educating and training project of outstanding engineers; electrical engineering and automation; training mode; selection approaches

\section{INTRODUCTION}

Many higher education institutions focus on research and exploration of training outstanding engineers in different professional field at present to implement the educating and training project of "outstanding engineers", organized by ministry of education combined with related guilds in June, 2010.

The major of electrical engineering and automation mainly studies production, transmission, distribution and application of electricity and any other related problems about it in science and technique. A remarkable characteristic about this major is the abstruseness of the theory and conception, which always makes students unreadable. Combining theory with practice is an effective way for students to master knowledge and eventually become engineering application talents by inspiring the positive learning and enhancing the innovative awareness. At the same time, the scale and equipment level of the power industry reaches international leading level in China, but we starve for a set of advanced engineering talents who can play the leading role in manufacture, operation and maintenance technology of large-scale power equipment, large-scale wind and solar power generation, intelligent instrument, energy conservation and emission reduction technology, and so on. That brings us new challenge in development direction and speciality system structure for electrical engineering and automation in each college. The question urgently needed to be solved under new situation is how to train outstanding engineers and adapt to the development requirements of electric power system by using their innovation and engineering practical capability $^{[1]}$.

Electrical engineering and automation of Chongqing university of technology(electric specialty of CQUT for short) built in 2004, has good enrollment and employment situation $^{[2]}$. The graduates have got widely consensus by domestic and foreign experts, related organizations and societiy. Electric specialty of CQUT became the experimental unit of "outstanding engineers" training plan in the end of 2009 of the school and has had several favorable effects and received some useful experience. This paper then discusses the training mode, the standard for student selection and the implementation approaches of the “outstanding engineers” project.

\section{TRAINING MODE FOR OUTSTANDING ENGINEERS IN THE ELECTRIC SPECIALTY OF CQUT}

With plan for training outstanding engineers carried out by ministry of education, each universities and colleges in China are exploring training scheme in different professional fields. In order to train technical talents with high comprehensive quality, solid professional foundation and strong social adaptation ability, to meet requirements for talents of economic development, most training modes based on foreign mature modes, surrounded with related element, establish teaching syllabus for knowledge, ability and quality according to our national conditions and our college teaching targets.

In order to adapt fast development of power and related industry, to meet further requirements for talents in electrical engineering and automation specialty of country and industry, " $2+1+1$ " training mode for outstanding engineers has been adopted to electric specialty of CQUT, as shown in Fig.1. 


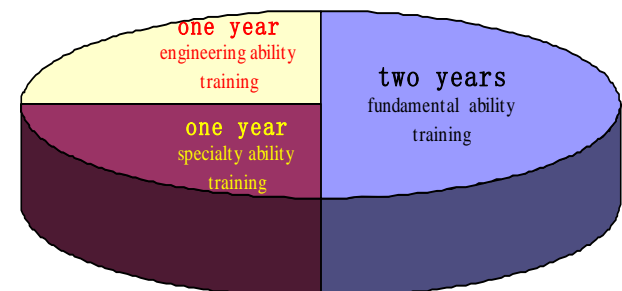

Figure 1 Outstanding engineer training mode for electric specialty of CQUT

\section{A. Fundamental ability training within two years}

To training students' fundamental ability, electric specialty of CQUT focuses on kernel fundamental theory, fundamental knowledge and necessarily fundamental skills and methods, acting on professional career, to lay a foundation of life-long learning. Three modules are given to implement the contents mentioned above: public basis, subject basis, and specialized basis, shown in Fig.2. The last two modules center on core courses, recombine and integrate other courses (include crosswise integration and longitudinal integration), enhance the cohesion and overall coordination with each other. The point is not just to emphasize the knowledge factors and units of professional knowledge system, but also to emphasize the knowledge relevance and integrity, to promote students to make innovation with new thoughts and new methods, to master each useful tools, to understand engineering background and subject forefront information earlier. By conducting these training approaches, it is supposed to lay a solid foundation for the students' engineering capability.

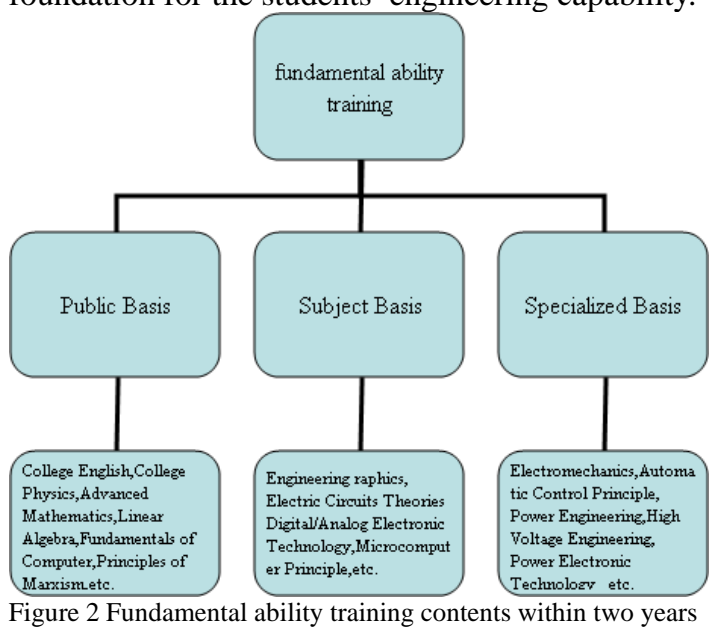

\section{B. Specialty ability training within one year}

There are two specialty directions about electric specialty of CQUT: electric power system and power electronics and drive. Students training for outstanding engineers learn major courses according to each specialty direction they chose previously. In this stage, for theory courses studying, experts of enterprise may be invited to school to give students some teaching instruction or lead students to their production field to study professional knowledge in practice depending on each course characteristics. Teachers in school may process courses in the form of projects. These can all improve teaching quality, cultivate students to have engineer basic quality and specialty ability skilled, solve the teaching problem for combination of theory and practicing, make positive interaction of personal cultivation and social requirements. For practice courses teaching, on the other hand, may be implemented by means of curriculum designs, integration design, experiments, and so on.

\section{Engineering ability training within one year}

Engineering ability training, running through the third and fourth academic year of electric specialty in CQUT, includes two aspects: basic engineering ability training and comprehensive engineering ability training. The former requires students to grasp electric basic knowledge, such as mark identification, diagram drawing, equipment connection, debugging, repairing and maintenance. It also requires students to do professional and social practice in corporation in order to have a preliminary understanding of the professional nature, industry application, working environment, corporation culture, etc. At the same time, students could learn advanced technology, concept and equipment about electric specialty in enterprise, could be trained to have engineering practice ability and management ability, to have spirit of team cooperation, to have interpersonal communication ability and to have professional ethics. The social adaptability could be enhanced, as well as working experience be accumulated. Further more, experiment teaching step is irreplaceable in outstanding engineers' education, because opening experiment is not only favorable to individual thinking, but also good for exciting learning enthusiasm and creative thought.

Comprehensive engineering ability training mainly includes electric integration design and graduation design. Each student has two teachers guiding them: teacher in school and teacher in corporation, the so-called double tutors system. The implementing scheme takes project driving mode, and teachers are all responsible for whole process in students training. That is, teachers from school and corporation make the specific corporation training plan together, and instruct students to accomplish the practice step together, such as course designs and graduation design.

\section{STUDENTS' SELECTION APPROACHES OF ELECTRIC SPECIALTY OF CQUT}

\section{A. selection principle}

Selecting students with development potential, excellent both in conduct and learning, aspiring in technological innovation or engineering practice work ${ }^{[3]}$ and training them to be excellent engineering personnel having innovation and practice ability, is the precondition for outstanding engineering training plan to implement successfully. 
First of all, the entire selection work should follow the principle of personal wishes; explain the training precept, scheme and advantage to students; make students understand the whole training process before selection. Then students can sign up for different specialty directions according to their learning situation and interests. Secondly, selection work should carry out with principle of "openness, fairness and justness", which means information publicity, process specification and effective communication. Finally, using comprehensive quality as reference standard, students are selected under the principle of competitive merits.

\section{B. selection time}

The exact time for selection is different in different colleges. Some universities choose the time right after the students' entrance to university; others in freshman year or sophomore year. CQUT recruits students under the policy of great specialty of “electric information" since 2010, providing students more time to understand characteristics of every specialty and selection space. With this policy, students recruited in great specialty of "electric information" have the same teaching plan in freshman year or sophomore year, chose specialty in the second term of sophomore year according to personal interests and personal advantages. Therefore, outstanding engineers' selection work and specialty distributaries of great specialty of "electric information" are carried out simultaneously in CQUT. Every student in great specialty of "electric information" has equal opportunity to be selected for outstanding engineers training plan. To ensure cultivation quality and efficiency, only 20 students are chose for training plan of electrical engineering and automation.

\section{C. selection procedure}

To ensure training efficiency, selection procedure of outstanding engineers was gestated through repetitious discussing and finally determined by college leaders and professional teachers, shown in Fig.3.

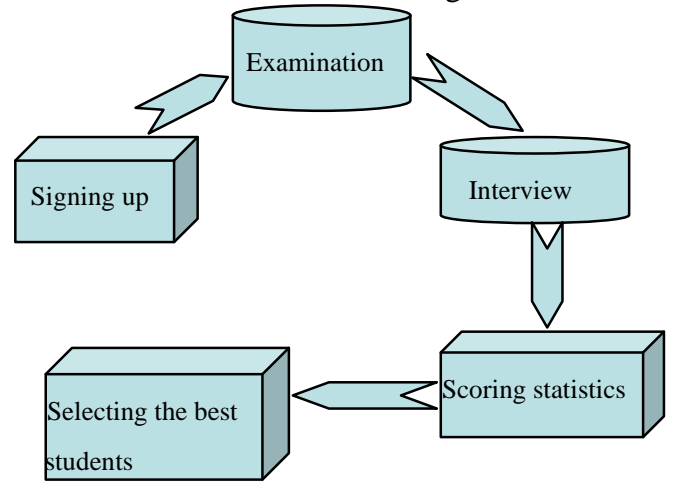

Figure 3 Selection procedure of outstanding engineers

Signing up is the first step of implementation of the training plan. Students with good moral character and physical health can all sign them up. Then written examination, based on situations of enlists, will be organized by academy. Four aspects contained therein: mathematics, electric circuit theories, digital electronic technology and analog electronic technology. The last step is interview performed by experts, which consist of knowledge architectonic, logic ideation, expression ability, group cooperation and practical ability, otherwise, awarded of science and technology competition is added to this part of score too. With the total score ten points, the integrated grade of all courses in first and second academic year accounts for four points, the written examination for three, and the interview for three. After all of these procedures, scoring statistics and ranking will been done, then the best 20 students are selected before results announced to public.

\section{PRACTICE AND EXPLORATION OF THE TRAINING PLAN IN ELECTRIC SPECIALTY OF CQUT}

Outstanding engineers would be not only provided with sturdy foundation and professional knowledge, but also with stronger engineer practice ability and creativity for the future. As theory is the basic of doing engineer work and solving real problem in practice. Besides, engineer practice ability can induct and intensify cognition and application of theoretic knowledge for students, help them combing theory with practice.

In colleges and universities of China, most students do theory learning but seriously lack of engineering practice training for a long time. According to the training plan in electric specialty of CQUT, “double tutors" ${ }^{[4]}$ are adopted in all the practice processes, which are responsible for the whole training process talked above. At the beginning of third academic year, students in training plan are grouped for different tutor teams by divergent selection and then be assigned for the first period of training. Since an eligible electric engineer should understand the standards and rules of electric industry, as well as provided with engineering basic knowledge such as mark identification and diagram drawing $^{[5]}$, the first period of training work includes mark identification, diagram drawing, equipment connection, debugging, repairing and maintenance. After having primary recognition of engineer practice, students would be trained by means of project driving mode proceed by scientific research project from school or engineering project from corporation in the second period of training work. The target is for students to learn to combine theory with practice, solve real problem in practice using professional knowledge, and be familiar with project developing process and management and to enhance the ability of products design and creation. The third or last period of training work focus on quality training such as professional ethics, team cooperation, and engineering management.

\section{CONCLUSION}

Putting plan of training “outstanding engineers” into practice can not only integrate education sources of college 
and corporation, but can also arouse students' interest in learning, and make them master engineering foundation and be provided with basic engineering practice ability, humanistic scientific literacy, the spirit of team cooperation, management and interpersonal communication ability. Moreover, it will enhance their social competition ability as well. As a result, students then can adapt to the development of social requirements. Meanwhile, as a mid-long term education reform and development planning program in our country, outstanding engineers training plan has important significance for improving education quality and engineering ability, and accelerating China development in being a powerful country in the field of engineering education.

\section{REFERENCES}

[1] Zhou Yan, Guo Qiangang, Xie Jun and so on. Exploration of "educating and training plan for outstanding Engineers" on electrical engineer, China University Teaching, PP.5-6, December, 2011.

[2] Liu Wei, He Hiaorong, He Juan. "Exploration of the plan mode of training outstanding engineers in department of electrical engineering”. China Electric Power Education, PP.58-60, June, 2012.

[3] Liu Hua-yan, Mao Xiao-yuan, Xiang Bin, Xiao Chun, Ai Ning. "Screening procedure of students into "A Plan for educating and training outstanding engineers" project”. Modern Property Management, vol11, PP.70-73, January, 2010.

[4] Zhang Anfu,Liu Xingfeng. "Reflection on the Implementation of "A plan for Educating and Training Out-standing Engineers"”. Research in Higher Education of Engineering, PP.56-59, April, 2010.

[5] He Zhiyuan, Zheng Yuzhen. "Thinking and exploration of training outstanding "field electrical engineer"'”. China University Teaching, PP.23-25, March, 2011. 